\title{
EXONERAÇÃO A PEDIDO DE PROFESSORES: ESTUDO EM DUAS REDES MUNICIPAIS PAULISTAS
}

\author{
Nathalia Cassettari ${ }^{*}$ \\ Valdelice de Fátima Scaldelai ${ }^{* *}$ \\ Patrícia Cristina Frutuoso ${ }^{* *}$
}

\begin{abstract}
RESUMO: O presente estudo tem como objetivo identificar características comuns entre os professores que pediram exoneração nas redes municipais de educação de São Bernardo do Campo e Diadema, bem como compreender os motivos que os levaram a tomar tal decisão. A pesquisa foi realizada por meio de questionário semiestruturado e, no total, obteve 74 respondentes. Os resultados da pesquisa indicam similaridades entre a maioria dos respondentes das duas redes: são professoras, com idade entre 26 e 45 anos, que pediram exoneração do cargo de professor para exercerem outras atividades dentro da mesma rede de ensino ou para exercerem a docência em outras redes que apresentavam melhores condiçôes de trabalho e remuneração.
\end{abstract}

Palavras-chave: Trabalho docente. Exoneração a pedido. Retenção de professores. Condiçóes de trabalho.

\section{TEACHER ATTRITION: A STUDY IN TWO MUNICIPALITIES IN THE STATE OF SÃo PAUlo}

\begin{abstract}
The present study aims to identify common characteristics among the teachers who resigned their positions within the educational system of Sao Bernardo do Campo and Diadema, in the State of Sao Paulo, Brazil, as well as understand the reasons that led them to this decision. The research was conducted through a semi-structured questionnaire and had 74 respondents in total. Even though the results may not be generalized, they do indicate similarities between the majority of respondents of both school systems: they are female, aged between 26 and 45, who asked to be discharged from their teaching position in order to perform other activities within the same school system or to work as teachers in a different school system which presented better working and/or paying conditions.
\end{abstract}

Keywords: Teaching. Teacher attrition. Teacher retention. Working conditions.

\footnotetext{
* Universidade de São Paulo, Faculdade de Educação, São Paulo, Brasil. E-mail de contato: nathalia. cassettari@gmail.com.

** Rede Municipal de Ensino de São Bernardo do Campo. São Bernardo do Campo, São Paulo, Brasil.
} 


\section{DÉMISSION DES ENSEIGNANTS: UNE ÉTUDE DANS DEUX MUNiCipalités de L'ÉTAT de SÃo PaUlo}

RÉSUMÉ: Cette étude vise à identifier les caractéristiques communes entre les enseignants qui ont démissioné de l'éducation municipale à São Bernardo do Campo et à Diadema, bien qu'à comprendre pour quelles raisons ils en ont pris cette décision. La recherche a été réalisée par un questionnaire semistructuré, qui a été répondu par 74 personnes. Les résultats de l'enquête, même s'ils ne peuvent pas être généralisés, ils révélent des similitudes entre la plupart d'interviewés dans les deux villes concernées: ce sont des femmes, entre 26 et 45 ans, qui ont donné leurs démissions car elles voulaient faire d'autres activités liées à l'éducation ou pour être enseignante dans un autre établissement proposant de meilleures conditions de travail et rémunération.

Mots-clés: Le travail d'enseignant. Licenciement. Rétention des enseignants. Conditions de travail.

\section{Introdução}

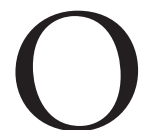

trabalho docente tem ocupado posição de destaque nas discussóes e políticas educacionais, sendo apontado como um dos principais fatores que contribuem para a construção de uma educação de qualidade. Assim, é crescente a preocupação com a atração de bons profissionais para a docência, bem como com a formação e retenção nos sistemas de ensino.

Cabe ressaltar que são questôes correlatas, uma vez que de nada adianta atrair e reter professores malformados, ou atrair e formar professores que não permanecerão em seus cargos. Além disso, muitos dos fatores que podem tornar a docência mais atraente também podem incentivar a permanência dos professores nessa profissão. Segundo relatório da $\operatorname{OCDE}$ (2006, p. 180) intitulado Professores são Importantes,

[...] salários competitivos, boas condiçôes de trabalho, satisfação no trabalho e oportunidades de desenvolvimento aumentarão o apelo da docência, tanto para novos professores, quanto para equipes já empregadas.

O enfoque desse trabalho é sobre a retenção na carreira, partindo do princípio que entender os motivos que levam os professores a pedirem exoneração pode contribuir para a elaboração de políticas que ajudem a mantê-los nas redes de ensino. Nesse sentido, as seguintes questóes motivaram o presente estudo: o que leva professores a pedirem exoneraçáo de suas redes de ensino? É possível 
estabelecer algumas características comuns entre eles? O que pode ser feito para mantê-los na profissão?

Para responder a essas questôes foram encaminhados questionários semiestruturados para professores que pediram exoneração do cargo nas redes de São Bernardo do Campo e Diadema. No caso de São Bernardo do Campo foram colhidas informaçóes sobre os professores que pediram exoneração entre janeiro de 2009 e julho de 2011. De um total de 558 professores exonerados no período, 35 responderam. Em Diadema a pesquisa abrangeu o período de janeiro de 2010 a julho de 2011, totalizando 122 professores exonerados e 39 respondentes.

É preciso considerar que a exoneração de professores traz custos significativos para o sistema de ensino, pois torna-se necessário substituí-los e assim replicar os custos com contratação e formação. A rotatividade também acarreta prejuízos para a construção de uma equipe coesa dentro das escolas, para o estabelecimento de relaçóes duradouras com a comunidade escolar e para a aprendizagem dos alunos, o que justifica a necessidade de estudos e políticas que tenham como foco a retenção de professores.

A primeira parte do artigo apresenta uma breve análise da literatura relacionada à retenção de professores. Vale dizer que o número de pesquisas voltadas a esse tema no Brasil é ainda bastante restrito, merecendo destaque o estudo de Lapo e Bueno (2002, 2003), que analisaram os pedidos de exoneração dos professores da rede estadual de São Paulo, entre os anos de 1990 e 1995.

A segunda parte do trabalho trata da metodologia da pesquisa, bem como, de seus principais resultados, buscando caracterizar os professores que pediram exoneração e compreender os motivos que os levaram a tal decisão. Por fim, foram levantadas algumas consideraçóes relacionadas ao tema proposto.

\section{Retenção de professores}

O debate acadêmico sobre a retenção de professores envolve discussóes tanto sobre a permanência desses profissionais nas redes de ensino, quanto de sua manutenção em uma mesma escola. Ingersoll e Smith (2003) salientam a existência de duas vertentes dentro dessa temática: a primeira discute o abandono (attrition) - professores deixam a profissão docente para exercerem outras atividades -, a segunda discute a rotatividade (migration) - professores permanecem na profissão, mas mudam de escola. Com relação à primeira vertente, é possível identificar mais uma divisão: aqueles que abandonam a docência para se dedicarem a outras funções dentro do sistema educacional (coordenação, supervisão, direção etc.) ou para se dedicarem a outras ocupaçóes (remuneradas ou não). 
Para Lapo e Bueno (2003) o abandono do trabalho docente é o desfecho de um processo que se concretiza ao longo de vários anos, nos quais os vínculos com a profissão vão sendo enfraquecidos por conta de uma série de insatisfaçóes, fadigas, descuidos e desprezos.

As autoras perceberam que o abandono definitivo da profissão só ocorre depois de os professores lançarem mão de "diferentes mecanismos de evasão", podendo-se citar:

- O abandono temporário, caracterizado pelo afastamento físico e emocional do ambiente de trabalho por meio de absenteísmos, licenças curtas (em geral por motivo de saúde) e licenças sem vencimentos;

- A remoção, em que os professores trocam de escola, permanecendo na mesma rede de ensino, em busca de melhores condiçóes de trabalho;

- A acomodação, entendida

[...] como o distanciamento da atividade docente mediante condutas de indiferença a tudo que ocorre no ambiente escolar, ou de um tipo de inércia, no sentido de buscar inovaçóes e melhorias no ensino, e um não envolvimento com o trabalho e com os problemas cotidianos da escola. (LAPO; BUENO, 2003, p. 84)

Uma questão presente em diversos estudos sobre a retenção de professores refere-se à identificação de características comuns entre os que abandonaram a profissão. A ideia é direcionar a política de retenção para os grupos que apresentam maior probabilidade de pedir exoneração.

O relatório da OCDE (2006) lista algumas características comuns aos profissionais que são mais suscetíveis a abandonarem a carreira nos países membros:

1. Lecionam nas séries finais do ensino fundamental e do ensino médio;

2. Apresentam melhor qualificação acadêmica;

3. Encontram-se no início da carreira;

4. Sexo masculino.

O relatório destaca ainda que a saída de professores tende a ser maior nas escolas que atendem os alunos de nível socioeconômico mais baixo, o que só reforça as desigualdades sociais e educacionais. 
Lapo e Bueno (2003) também buscaram identificar o perfil dos professores exonerados da rede estadual de São Paulo entre os anos de 1990 e 1995. Dos 29 professores que responderam à pesquisa 22 eram mulheres; a maioria possuía cursos de pós-graduação, sendo que o pedido de exoneração aconteceu próximo ou logo após a conclusão destes cursos; por fim, a maior parte dos respondentes só pediu exoneraçáo após um longo período de permanência na rede (mais de 10 anos).

Muitos trabalhos buscam ainda analisar os fatores que teriam contribuído para o abandono do magistério. Nesse sentido, os fatores mais comumente apontados podem ser classificados em 3 grupos: salário e carreira, condições de trabalho e motivaçóes pessoais. Vale dizer que as pesquisas indicam que na grande maioria das vezes a decisão pela exoneração envolve múltiplos fatores correlacionados.

No estudo de Lapo e Bueno (2003, p. 73), por exemplo, ainda que a baixa remuneraçáo tenha sido apontada pela maioria dos entrevistados como principal razão para a exoneração, em geral vem acompanhada de outros motivos "relacionados sobretudo à falta de perspectivas de crescimento profissional e às péssimas condições de trabalho, aspectos claramente decorrentes do modo como o Estado gere a educação e o ensino público".

Com relaçáo aos motivos de ordem pessoal, cabe destacar que muitas professoras deixam a profissão para ficar em casa cuidando dos filhos, o que merece especial atenção dos formuladores de políticas educacionais.

Trata-se de uma constatação significativa, uma vez que grande proporção dos professores iniciantes é constituída por mulheres jovens, o que sugere que uma estrutura abrangente de políticas eficazes deverá incluir os meios para ajudar os professores que têm família, oferecendo oportunidades para continuar a lecionar - por exemplo, com o apoio de creches e trabalho em período parcial - e para voltar à docência posteriormente. (OCDE, 2006, p. 187)

Também é comum que os professores deixem a sala de aula para ocuparem outras funções no sistema educacional em busca de melhores condições de trabalho e remuneração. De acordo com Morduchowicz (2003, p. 12):

Em geral, a estrutura atual [da carreira do magistério] remunera trabalhos bem definidos, não prevendo mecanismos de promoção dentro do mesmo cargo [...] De fato, isto implica que a carreira profissional docente náo dá oportunidades a quem queira alcançar uma distinção profissional, junto com o correspondente reconhecimento salarial, sem deixar suas atividades 
dentro do curso para assumir uma posição administrativa, de direção ou supervisão. Isto pode ocorrer mesmo nos casos em que o professor deseje permanecer em aula, onde talvez se sinta mais confortável e em uma função que considere ser o trabalho para o qual se preparou. Este é, claramente, um caso que não beneficia nem o professor, nem o setor educativo e, por conseguinte, tampouco a sociedade.

Nesse mesmo sentido, Vaillant (2006, p. 43) afirma que na carreira docente "só se permite a ascensão a outros postos mediante o afastamento da classe, o que tem como consequência perversa o abandono da tarefa de ensinar por parte dos bons professores".

O abandono do magistério por parte dos professores tem consequências nefastas, sintetizadas pelo relatório da $\operatorname{OCDE}$ (2006, p. 186) da seguinte maneira:

As escolas e os sistemas envolvidos são obrigados a arcar com os custos de captação, recrutamento e iniciação de grande número de novos professores; os estudantes enfrentam alta reposição de professores e possivelmente perdem em termos de continuidade de programa; e a constatação de que as taxas de vacância são maiores em localidades pouco favorecidas sugere que há um acúmulo de problemas educacionais e um aumento da desigualdade entre as escolas.

Segundo dados disponibilizados no site da Alliance for Excellent Education (http://all4ed.org), tanto o abandono da profissáo docente quanto a rotatividade dos professores geram custos altíssimos para os sistemas de ensino. Estima-se que os gastos com a reposição dos professores que desistiram da profissão, nos Estados Unidos, sejam de aproximadamente US\$ 2.2 bilhóes por ano, e os gastos com a reposição dos professores que pediram transferência de escola, de aproximadamente US\$ 2.7 bilhóes por ano. Uma instituição norte-americana criou um simulador dos custos e o gasto estimado girou em torno de US\$ 8.400 para a substituição de cada professor, dentro das escolas urbanas (Simulador disponível no site http://nctaf.org/teacher-turnover-cost-calculator/).

Além desses custos, a evasão de professores traz prejuízos para a aprendizagem dos alunos, para a construção de equipes coesas nas escolas e para a relação das escolas com as famílias, interferindo negativamente na qualidade da educação oferecida à população. A cada pedido de exoneração as escolas ficam sem professores até que um novo docente lhes seja atribuído. Após esse período, que pode ser mais ou menos demorado, de acordo com as características de cada rede de ensino, é preciso todo um esforço de diretores, coordenadores pedagógicos 
e demais professores para que o novo professor possa se inserir na dinâmica da escola, em seus processos formativos etc.

Todos esses fatores indicam a urgência de mais estudos e políticas que tenham como foco a retenção de professores. Cabe ressaltar que um dos possíveis motivos para o número reduzido de pesquisas sobre a retenção de professores no Brasil deve-se à dificuldade de obtenção de dados que permitam acompanhar o percurso de cada professor ao longo de sua vida profissional, sendo ainda mais difícil a obtenção de dados sobre os professores que pediram exoneração. Outro motivo pode ser atribuído ao grande número de professores precários e temporários, uma vez que "fica difícil saber se esses professores não estão mais na rede por vontade própria ou por falta de vagas”. (LAPO; BUENO, 2003, p. 68)

$\mathrm{Na}$ parte seguinte serão apresentados a metodologia e os principais resultados da pesquisa realizada com professores que pediram exoneração das redes municipais de São Bernardo do Campo e Diadema.

\section{A pesquisa}

Conforme anunciado anteriormente, essa pesquisa foi motivada por três questôes: quais motivos fazem professores pedirem exoneração de suas redes de ensino? Quais as características comuns entre esses professores? Quais providências poderiam mantê-los na profissão?

Dois municípios paulistas foram selecionados: Diadema e São Bernardo do Campo. As duas cidades fazem parte da região metropolitana de São Paulo, mais especificamente, do "ABCD" - região que ficou conhecida pelo desenvolvimento industrial, fruto da instalação das primeiras indústrias automobilísticas no Brasil. Apesar da proximidade física, as duas cidades possuem características distintas, conforme demonstram os dados abaixo:

\section{Tabela 1}

Informações estatísticas sobre os municípios

\begin{tabular}{|l|c|c|}
\cline { 2 - 3 } \multicolumn{1}{c|}{} & Diadema & Sáo Bernardo do Campo \\
\hline População (2010) & 386.089 & 765.463 \\
\hline Área da unidade territorial & $30,840 \mathrm{Km}^{2}$ & $408,773 \mathrm{Km}^{2}$ \\
\hline PIB (2009) & 9.969 .819 & 28.935 .767 \\
\hline PIB per capta (2009) & $25.066,30$ & $35.680,05$ \\
\hline IDH (2000) & 0,79 & 0,83 \\
\hline
\end{tabular}

Fonte: IBGE; PNUD. 
Com base nas informaçóes apresentadas, destacam-se as melhores condiçôes de São Bernardo do Campo nos indicadores socioeconômicos. Contudo, ao analisarmos os indicadores educacionais, essas diferenças tornam-se bem menos acentuadas. O Ideb de São Bernardo foi de 5.1 em 2007 e 5.6 em 2009, enquanto que o de Diadema foi de 5.0 em 2007 e 5.2 em 2009.

As duas redes municipais de educação também possuem características distintas. De acordo com os dados do IBGE Cidades, a rede de São Bernardo do Campo possui 142 estabelecimentos de ensino, 2.384 docentes e 67.930 matrículas. Já a rede de Diadema possui 86 estabelecimentos de ensino, 699 docentes e 18.772 matrículas. Os dados não representam a totalidade das redes municipais, uma vez que referem-se exclusivamente às pré-escolas e ao ensino fundamental regular, mas permitem comparaçóes sobre as dimensóes das duas redes.

Para o desenvolvimento deste trabalho optou-se por delimitar o estudo aos professores efetivos das duas redes. No caso de Diadema, considerou-se também os professores da suplência II, por serem concursados, o que lhes garante estabilidade de emprego.

Segundo dados fornecidos pelas Secretarias Municipais de Educação, o número de pedidos de exoneração de professores tem crescido nos últimos anos. Em Diadema durante o ano de 2010 ocorreram 53 pedidos de exoneração; enquanto que apenas no primeiro semestre de 2011, foram 69 professores que deixaram a rede ou um de seus cargos.

Em São Bernardo do Campo os números são ainda mais significativos. No ano de 2009 foram 108 professores a deixarem as salas de aula, a maioria no início do ano letivo. Em 2010, 288 cargos foram deixados vagos e, até a metade do ano de 2011, 162 professores já haviam pedido exoneração. É preciso considerar que no período analisado foi realizado neste município o primeiro concurso para provimento do cargo de coordenador pedagógico $(\mathrm{CP})$, gerando uma considerável movimentação - principalmente no início do ano letivo de 2010. A mudança de cargo não implica em abandono da carreira do magistério, porém, bons professores deixaram a sala de aula.

Em síntese, o universo da pesquisa compreendeu 558 professores que pediram exoneração entre janeiro de 2009 e julho de 2011 da rede municipal de educação de São Bernardo do Campo e 122, entre janeiro de 2010 e julho de 2011, da rede municipal de educação de Diadema.

O passo seguinte do trabalho foi a busca de informaçóes que possibilitassem o contato com esses profissionais. Cabe destacar a iniciativa da Secretaria Municipal de Educação de Diadema ao coletar, no momento da exoneração, informaçóes sobre os professores e os motivos dessa decisão, facilitando o contato posterior. 
Já a Secretaria Municipal de Educação de São Bernardo do Campo limitou-se a fornecer a listagem dos nomes dos professores exonerados e das escolas em que atuavam, tornando necessário o contato com todas as escolas listadas para obtenção de informaçôes.

Assim, de um total de 680 professores exonerados (558 em São Bernardo do Campo e 122 em Diadema), 149 foram contatados pela pesquisa (81 em São Bernardo do Campo e 68 em Diadema). Para todos esses profissionais foram encaminhadas cartas explicando os motivos da pesquisa e questionários autoaplicáveis com 14 perguntas fechadas e uma aberta.

O questionário buscava traçar o perfil desses profissionais, levantar as informaçóes ocorridas no período compreendido entre sua entrada e saída da rede, identificar o tipo de ocupação que está exercendo no momento, verificar o grau de satisfaçáo com a sua decisão de pedir exoneração e entender os motivos que influenciaram sua decisão de ingressar e sair da rede. Através de questão aberta, os professores foram solicitados a indicar, caso existissem, quais os fatores que precisariam ser satisfeitos, considerando-se a possibilidade de retorno à rede.

Responderam ao questionário, no prazo estabelecido pelas pesquisadoras, 74 professores, sendo 39 em Diadema e 35 em Sáo Bernardo do Campo. Vale dizer que boa parte dos respondentes encaminhou, junto com os questionários, mensagens com informaçôes complementares, palavras de incentivo à pesquisa e solicitaçóes de retorno dos resultados obtidos. Como os dados não foram coletados por amostragem, não foi possível realizar generalizações, contudo, eles trazem informaçóes relevantes para o estudo, que serão apresentadas a seguir.

\section{Apresentação e análise dos dados}

Apesar de em ambas as redes existirem professores do sexo masculino, $100 \%$ das respondentes da pesquisa são do sexo feminino. As duas redes incluem respondentes de todas as faixas etárias, contudo, em Diadema a maior parte das participantes se concentrava na faixa etária de 26 a 35 anos de idade (43,6\%), enquanto em São Bernardo do Campo a predominância foi no intervalo entre 36 e 45 anos de idade (60\%). Somadas essas duas faixas etárias (de 26 a 45 anos), temos $82,9 \%$ das respondentes em São Bernardo do Campo e 76,9\% em Diadema.

Também encontramos respondentes em todas as faixas correspondentes ao tempo de atuação na rede, como demonstra a Tabela 2.

Os dados demonstram situaçóes muito diferentes entre as duas redes. Em Diadema, 46,2\% pediu exoneraçấo nos dois primeiros anos de exercício da profissão, corroborando com a tendência internacional apresentada no relatório da OCDE (2006). Em São Bernardo do Campo, 62,9\% permaneceu na rede 
entre 5 a 15 anos, ratificando os dados encontrados por Lapo e Bueno (2003). Esta alta porcentagem em São Bernardo do Campo pode estar relacionada ao concurso para o cargo de coordenação pedagógica.

\section{Tabela 2}

Tempo de atuação como professora nas redes $(\mathrm{em} \%)$

\begin{tabular}{|l|c|c|}
\cline { 2 - 3 } \multicolumn{1}{c|}{} & Diadema & Sáo Bernardo do Campo \\
\hline Até 5 anos & 64,1 & 20,0 \\
\hline De 5 a 10 anos & 10,3 & 34,3 \\
\hline De 10 a 15 anos & 15,3 & 28,6 \\
\hline Mais de 15 anos & 10,3 & 17,1 \\
\hline
\end{tabular}

Fonte: Elaboração própria baseada nas respostas obtidas pelos questionários.

Quanto a exercer mais de uma atividade remunerada antes do pedido de exoneração, temos que em Diadema, 71,8\% e, em São Bernardo do Campo, $77,2 \%$ dos respondentes afirmaram acumular pelo menos dois cargos na mesma rede de ensino, ou em redes de ensino diferentes (públicas ou privadas), ou atuar em outras ocupaçóes como tradutora ou vendedora.

\section{Tabela 3}

Formação acadêmica no ingresso e exoneração (em \%)

\begin{tabular}{|l|c|c|c|c|}
\cline { 2 - 5 } \multicolumn{1}{c|}{} & \multicolumn{2}{c|}{ Diadema } & \multicolumn{2}{c|}{ São Bernardo do Campo } \\
\cline { 2 - 5 } \multicolumn{1}{c|}{} & Ingresso & Exoneração & Ingresso & Exoneração \\
\hline Magistério Ensino Médio & 25,7 & 2,5 & 34,3 & 2,8 \\
\hline Nível Superior & 64,1 & 59 & 42,8 & 31,4 \\
\hline Pós- Graduaçăo & 10,2 & 38,5 & 22,9 & 60 \\
\hline
\end{tabular}

Fonte: Elaboração própria baseada nas respostas obtidas pelos questionários.

Desnecessário afirmar que o acúmulo de mais de uma jornada de trabalho gera desgaste para os professores e diminui o tempo disponível para o lazer, para a convivência familiar e para a atualização profissional e cultural. Deste modo, "o magistério não facilitaria mais do que outras profissôes a conciliação entre vida doméstica e profissional, uma das justificativas ainda hoje apontadas como uma das razóes da feminização da categoria”. (GATTI; BARRETO, 2009, p. 21) Além disso, o acúmulo de cargos traz prejuízos ao trabalho docente, uma 
vez que diminui o tempo dedicado à avaliação dos alunos, planejamento e preparo das aulas.

Outra pergunta do questionário diz respeito à formação acadêmica quando do ingresso e da saída da rede de ensino. Foram apresentadas várias alternativas para que indicassem nos dois momentos, aceitando-se mais de uma alternativa. A análise do grau mais elevado de formação indicado pelos professores permitiu observar, em ambos os casos, uma evolução.

Os dados indicam que houve uma grande diminuição do número de profissionais que possuíam apenas o magistério e um significativo aumento daqueles com cursos de pós-graduação. Deste modo, é possível inferir que as redes não estão conseguindo reter nas salas de aula os professores mais bem qualificados, o que corrobora as afirmaçóes do relatório da OCDE (2006) e do trabalho de Lapo e Bueno (2003). Essas autoras apresentam as seguintes explicaçóes para a exoneração de professores após o término de cursos de pós-graduação:

Esse fato talvez possa ser explicado de duas perspectivas: primeiro, pela ampliação de oportunidades no mercado de trabalho que esses cursos propiciam; segundo, pelo pouco reconhecimento ou valorizaçáo que é dado aos professores que possuem pós-graduação, na carreira do magistério público. (LAPO; BUENO, 2003, p. 03-04)

Interessante notar que a grande maioria das respondentes continuou na carreira do magistério após a exoneração, porém em outro cargo ou rede de ensino, conforme pode ser observado na tabela a seguir:

\section{Tabela 4}

Situação profissional atual (em \%)

\begin{tabular}{|l|c|c|}
\cline { 2 - 3 } \multicolumn{1}{c|}{} & Diadema & São Bernardo do Campo \\
\hline Professora em outra(s) rede(s) de ensino & 89,7 & 34,2 \\
\hline $\begin{array}{l}\text { Outro cargo dentro da mesma rede (direção, coordenação } \\
\text { pedagógica, assistente de direção) }\end{array}$ & 0 & 57,1 \\
\hline Professora na mesma rede, com uma matrícula a menos & 2,5 & 0 \\
\hline Outra atividade remunerada (fora do magistério) & 5,1 & 0 \\
\hline Nenhuma atividade remunerada & 2,5 & 5,7 \\
\hline Não informado & 0 & 2,8 \\
\hline
\end{tabular}

Fonte: Elaboração própria baseada nas respostas obtidas pelos questionários.

No caso de São Bernardo do Campo destaca-se o grande número de respondentes que atualmente ocupa outro cargo nesta mesma rede de ensino, o que 
pode ser explicado pela realização de um concurso para a coordenação pedagógica que resultou na mudança de cargo de 15 participantes da pesquisa $(42,8 \%)$. Com relação às professoras que assumiram cargos em outras redes de ensino, seis foram para a rede municipal de São Paulo; quatro foram para outras redes municipais do ABC; uma foi para a rede estadual de São Paulo e outra ainda passou a atuar em uma universidade e em uma escola particular.

Em Diadema, 89,7\% optaram por assumir cargos em outras redes de ensino. Destas, 60\% foram para a rede municipal de São Paulo; 28,6\% para a rede municipal de São Bernardo do Campo; 8,6\% para a rede estadual de São Paulo e $2,8 \%$ para outras redes de ensino.

Partindo do pressuposto que a decisão pela exoneração tem impacto sobre o salário dos professores, perguntou-se às participantes a qual faixa salarial pertenciam de acordo com a última remuneração antes do pedido de exoneração e a percebida atualmente, o que permitiu observar a seguinte situação:

\section{Tabela 5}

Remuneração atual em relação à recebida antes da exoneração (em \%)

\begin{tabular}{|l|c|c|}
\cline { 2 - 3 } \multicolumn{1}{c|}{} & Diadema & Săo Bernardo do Campo \\
\hline Aumentaram ao menos uma faixa salarial & 51,4 & 34,3 \\
\hline Permaneceram na mesma faixa salarial & 30,8 & 37,1 \\
\hline Reduziram ao menos uma faixa salarial & 15,3 & 20,0 \\
\hline
\end{tabular}

Fonte: Elaboração própria baseada nas respostas obtidas pelos questionários.

Destaca-se o fato de que uma grande parcela das respondentes não obteve um aumento salarial significativo, sendo considerável o número de professoras com salário reduzido após a exoneração, deixando implícito que existem outros fatores, além da remuneração, que influenciam a decisão.

Parte das professoras com redução salarial abandonou o emprego e hoje não exerce qualquer atividade remunerada, outra parte optou por apenas uma matrícula na rede - nestes casos, a redução da carga horária de trabalho foi apontada como fator compensador - e, por fim, algumas professoras, ao assumirem novos cargos (seja dentro da mesma rede de ensino ou em uma rede diferente) deixaram de ganhar adicionais que faziam diferença na composição da sua remuneração. Muitas das professoras que assumiram novos cargos creem na possibilidade de um incremento salarial futuro - justificado por melhores planos de carreira. 
Vale dizer que a decisão pela redução salarial não é uma decisão fácil, visto que $53 \%$ das participantes da pesquisa de Diadema e $37,1 \%$ das participantes de São Bernardo do Campo informaram que contribuem com a maior parte da renda familiar, que corrobora os dados analisados por Gatti e Barreto (2009). Segundo essas autoras, serve para desmistificar o papel social atribuído às professoras como dependentes do marido e da profissão docente como ocupação tipicamente feminina, complementar às atividades domésticas.

Em duas questóes foi solicitado às participantes que indicassem os fatores que influenciaram a decisão de ingressarem e de se exonerarem das redes de ensino. As questôes solicitavam que as participantes valorassem (considerando 0 para "nenhuma influência" e 5 para "muita influência") os fatores listados, havendo a opção de inclusão de outros fatores.

Nos fatores que motivaram o ingresso, a similaridade dos resultados entre as duas redes é impressionante, conforme demonstrado na Tabela 6.

\section{Tabela 6}

Motivos para ingresso na rede

\begin{tabular}{|l|c|c|}
\hline \multirow{2}{*}{\multicolumn{1}{|c|}{ Fatores }} & \multicolumn{2}{c|}{ Ordem de Importância } \\
\cline { 2 - 3 } & São Bernardo do Campo & Diadema \\
\hline Necessidade Financeira & 1 & 2 \\
\hline Estabilidade no serviço público & 2 & 1 \\
\hline Remuneração & 3 & 3 \\
\hline $\begin{array}{l}\text { Facilidade em conciliar trabalho e } \\
\text { vida familiar }\end{array}$ & 4 & 4 \\
\hline
\end{tabular}

Fonte: Elaboração própria baseada nas respostas obtidas pelos questionários.

Nas duas redes de ensino foram citados fatores idênticos como aqueles que menos influenciaram a decisão de ingresso, inclusive na mesma ordem de importância: 1) Falta de opção de trabalho; 2) Influência de colegas e familiares que já eram funcionários da rede; 3) Facilidade para conciliar trabalho e estudo.

As diferenças entre as duas redes foram maiores quando analisadas as razões que mais influenciaram os participantes a pedirem exoneração. Em São Bernardo do Campo, conforme dito anteriormente, a realização de concurso para o cargo de coordenador pedagógico influenciou a saída de muitos profissionais do cargo de professor. Deste modo "assumir outro cargo dentro da própria rede de educação do município" foi o motivo apontado pelo maior número de participantes de São Bernardo do Campo. 
Entretanto, excluído este fator, as semelhanças voltam a aparecer. Nas duas redes a "Ausência/falta de perspectivas de crescimento profissional" e a "Remuneração" foram apontados como os fatores que mais influenciaram a decisão de pedir exoneração.

Os seguintes motivos foram apresentados como os que menos influenciaram a decisão pela exoneração das respondentes das duas redes (excluindo-se "Para assumir outro cargo dentro da própria rede de educação do município", que apareceu apenas em São Bernardo do Campo): 1) Dificuldade em engajar-se no grupo escola em que atuava; 2) Mudança de área de atuação (abandono da educação); 3) Atuação em outra modalidade de ensino; 4) Discordância com a proposta pedagógica e/ou concepçóes do trabalho da rede.

Foi perguntado ainda às professoras sobre o grau de satisfação com a decisão de sair da rede. A grande maioria das respondentes se disse satisfeita com a decisão (84\% na rede de Diadema e $85 \%$ na rede de São Bernardo do Campo). Algumas das insatisfeitas destacaram os motivos que as levaram a essa decisão, algumas vezes contra a sua vontade, como a impossibilidade de acúmulo de cargo em outra rede e a dificuldade de conciliar problemas de ordem pessoal.

Por fim, foi solicitado às professoras que indicassem, caso existissem, os fatores que precisariam ser satisfeitos para que fosse considerada a possibilidade de retorno ao cargo. Essa foi a única questão aberta do questionário e muitas das respondentes aproveitaram o espaço para dividir seus sentimentos, desejos e frustraçóes.

Dentre os fatores elencados como essenciais para um possível retorno, as respondentes enfatizaram, em sua grande maioria, questôes vinculadas à valorização da profissão expressa por meio de melhores salários, carreira e condiçóes de trabalho, conforme pode ser observado nas falas a seguir:

Com certeza, não teria saído do cargo de professora se a carreira tivesse evoluído, com melhor salário e valorização profissional. (Profa. C);

Valorização do magistério - digo isso, não só em obtenção de plano de carreira. Mas uma valorizaçáo efetiva. [...] sei da minha competência e sei que posso crescer em prefeituras ou outros estabelecimentos que valorizem seus profissionais pelo menos um pouco melhor. (Profa. B);

Há necessidade de reconhecimento e valorização pelo trabalho desenvolvido por parte da prefeitura, tanto no aspecto financeiro como no plano de carreira. Vale ressaltar que os pais e gestão escolar revelavam satisfação pelo trabalho desenvolvido por mim. (Profa. D); 
Melhor remuneração, um bom plano de evolução funcional, perspectiva de criação de concurso para novos cargos. (Profa. V);

Melhor estrutura física, material adequado, uma política pública para atender às expectativas e necessidades do profissional, além de melhores salários. (Profa. J).

As respondentes também elencaram, ainda que em menor número, questóes relativas à formação dos professores, ao acúmulo de cargos, à jornada de trabalho e à relação com a gestão escolar, dentre outras.

\section{Considerações finais}

O estudo mostra um número cada vez maior de professores que pediram exoneração nos dois municípios, evidenciando a necessidade de um esforço coletivo visando a compreensão dos motivos que os levaram a tomar essa decisão e a elaboração de soluçóes para esse problema.

Nesse sentido, destacam-se inciativas como a da Secretaria Municipal de Diadema de recolher informações, no ato da exoneração, sobre os motivos dessa decisão. Entretanto, nosso trabalho não teve como objetivo verificar como a Secretaria tem se apropriado destas informaçóes, cabendo aqui novos estudos que abordem a questão.

Por meio da análise dos questionários, constatou-se que existem características comuns entre a maioria dos respondentes, o que pode ajudar na identificação de grupos mais susceptíveis aos pedidos de exoneração. São elas: sexo feminino, com participação ativa na renda familiar, exercendo mais de uma atividade remunerada (incluindo aqui o acúmulo de cargos) e que ampliaram a sua formação acadêmica durante o período em que atuaram na rede. Não foi possível incluir nesse perfil dados sobre idade e tempo de atuação na rede, pois os resultados dos dois municípios foram divergentes.

Observou-se também que a grande maioria das respondentes continua atuando em profissões ligadas à educação pública, só que em outros cargos e/ou redes de ensino. Nesse sentido, é possível observar um movimento dos professores em direção a outras ocupaçóes ou redes de ensino que ofereçam melhores condiçôes de trabalho e remuneração. Tal movimento implica a saída dos professores da sala de aula, trazendo diversos prejuízos para as escolas e sistemas de ensino, conforme explicitado anteriormente.

Novas pesquisas poderão trazer uma compreensão melhor desse movimento e apontar os motivos que levam algumas redes a serem favorecidas em 
detrimento de outras, bem como alguns cargos (em especial de direção e coordenaçáo escolar) em detrimento do de professor. Contudo, os resultados do presente estudo podem ajudar a elaborar algumas hipóteses. A ênfase das respondentes na valorização profissional, expressa por melhores salários, carreira e condiçôes de trabalho, pode indicar que é isso que essas profissionais têm procurado ao mudarem de cargo ou de rede de ensino. Se esses requisitos tivessem sido atendidos, é possível que a exoneração de boa parte das respondentes fosse evitada.

Cabe destacar que "Remuneração" apareceu como um fator de maior influência na decisão de ingressar e de se exonerar das redes de ensino, podendo indicar um problema nos planos de carreira do magistério, que tem salários iniciais capazes de atrair uma parcela da população mas que, ao longo dos anos, vai perdendo a sua atratividade.

Gabriela Moriconi ao comparar o salário dos professores públicos com o de outros profissionais do setor público e privado, em diferentes momentos da carreira, percebeu que:

No período estudado, alguns grupos de professores públicos tiveram remuneraçóes relativamente melhores ou apenas um pouco menores do que outras ocupações no início da carreira, o que pode atrair indivíduos para a profissão do magistério. Porém para aqueles que já estavam nos últimos anos da carreira, essas remuneraçôes se mostraram bem menos competitivas. Isto pode gerar o abandono da carreira por aqueles que fizeram a escolha pelo magistério ou a falta de motivação e a busca por trabalhos secundários, o que pode atrapalhar o desempenho dos professores públicos no processo de ensino. (MORICONI, 2008, p. 64)

Este fato também pode ser comprovado pela "Ausência/falta de perspectivas de crescimento profissional" ter sido apresentada como um dos fatores que mais motivou a exoneração das professoras participantes da pesquisa. As falas a seguir expressam bem essa questão:

Quando entrei na prefeitura com o primeiro cargo tinha um salário considerado bom para trabalhar meio período, sendo uma recém formada do magistério e tendo 19 anos de idade. 8 anos depois porém, não tive nenhum aumento significativo, além de em outro município receber em um período o equivalente ao que eu recebia tendo duas matriculas nesta rede. (Profa. B)

Quando eu entrei na rede no ano de 2003, eu deixei a rede particular, o salário na rede na época era mais atrativo, porém com o passar dos anos o vi ficando em defasagem, bem como o plano de carreira que não saía do papel. (Profa. L) 
Acredito que estamos com uma defasagem salarial muito grande. Nosso salário inicial até pode ser melhor do que o de outras redes, mas em um ou dois anos trabalhando na rede de São Paulo, por exemplo, já dá para superar o salário inicial de São Bernardo do Campo. Além disso, tenho assistido a ótimos professores deixarem nossa rede, indo inclusive para a rede de Mauá, uma cidade muito menor. (Profa. M)

Digo que a rede municipal merece um plano de carreira que valorize verdadeiramente o professor, significando aumento real de seu salário (como ocorre em outras redes municipais da região) e o desejo de continuar participando do quadro de funcionários da Secretaria de Educação. Esse desejo que outrora era comum e forte entre os professores, vê-se hoje tornar-se frágil. (Profa. L)

Deste modo, a remuneração inicial é importante, mas não suficiente para manter os profissionais nas redes de ensino. Lapo e Bueno (2003, p. 05) chegaram às mesmas conclusóes em seu trabalho e ressaltam que:

É evidente a importância dos baixos salários, porém, se somada ainda a outros aspectos, como, por exemplo, as péssimas condiçóes de trabalho e a falta de perspectivas de crescimento profissional, aspectos esses também provenientes do tipo de gerência que é dada pelo Estado ao sistema educacional, a questão salarial se avoluma.

Nesse sentido, é significativo o fato de que algumas professoras terem o seu salário reduzido após a exoneração e ainda assim estarem satisfeitas com a decisão tomada, por representar uma reduçâo na jornada de trabalho, melhores condiçóes de trabalho ou uma carreira melhor estruturada.

Pensar na retenção de professores é pensar na valorização desses profissionais num sentido mais amplo, que contempla a sua remuneração, mas que vai além, considerando a oferta de um "ambiente que facilite o seu sucesso, garantindo também que desejem permanecer na profissão”. (OCDE, 2006, p. 180) Com base nesse entendimento as redes de ensino serão capazes de elaborar políticas públicas que consigam manter os professores nas salas de aula.

\section{Referências}

CASSETARI, N. Remuneração variável para professores: revisão da literatura e desdobramentos no Estado de São Paulo. 2010. Dissertação (Mestrado em Educação) - Faculdade de Educação - Universidade de São Paulo, São Paulo. 2010. 
FRUTUOSO, P. C. As razões pelas quais professores efetivos da rede municipal de São Bernardo do Campo deixam seu cargo: a questão da retenção na profissão docente. 2011. Trabalho de Conclusão de Curso de Pós-Graduação em Gestão Escolar - Faculdade de Educação - Universidade de São Paulo, São Paulo.

GATTI, B. A. et al. Atratividade da carreira docente. Estudos \& Pesquisas Educacionais, São Paulo: Fundação Victor Civita, n.1, p. 139-209, 2010.

GATTI, B.; BARRETO, E. Professores no Brasil: impasses e desafios. Brasília: Unesco, 2009.

INGERSOLL, R. M.; SMITH, T. M. The wrong solution to the teacher shortage. Educational Leadership, Alemanha, v. 60, n. 8, p. 30-33, 2003.

LAPO, F. R.; BUENO, B. O. O abandono do Magistério: vínculos e rupturas com o trabalho docente. Psicologia USP, Sáo Paulo, v. 13, n. 02, p. 243-276, 2002.

. O. Professores, desencanto com a profissão e abandono do magistério. Cadernos de Pesquisa, São Paulo, n.118, p. 65-88, 2003.

. O. Professores retirantes: um estudo sobre a evasão docente no magistério público do estado de São Paulo (1990-1995). In: Reunião da Associação Nacional de Pós-Graduação e Pesquisa em Educaçâo, 23., 2000, Caxambu.

LEMOS, J. C. G. Do encanto ao desencanto, da permanência ao abandono: o trabalho docente e a construção da identidade profissional. 2009. Tese (Doutorado) - Faculdade de Educação. Pontifícia Universidade Católica de São Paulo, São Paulo. 2009.

LOUZANO, P. et al. Quem quer ser professor? Atratividade, seleção e formação docente no Brasil. Estudos em avaliação educacional, São Paulo, v. 21, n.47, p.543-568, 2010.

MORDUCHOWICZ, A. Carreira, Incentivos e Estruturas Salariais Docentes. PREAL Programa da Reforma Educativa na América Latina e Caribe n. 23, jun. 2003. Disponível em http://www.oei.es/docentes/articulos/carreras_incentivos_estructuras_salariales_docentes morduchowicz portugues.pdf.

MORICONI, G. Os professores públicos são mal remunerados nas escolas brasileiras? Uma análise da atratividade da carreira do magistério sob o aspecto da remuneração. 2009. Dissertação (Mestrado) - Escola de Administração de Empresas - Fundação Getúlio Vargas, São Paulo. 2009.

OCDE. Professores são importantes: atraindo, desenvolvendo e retendo professores eficazes. São Paulo: Moderna, 2005.

SCALDELAI, V. F. Atratividade e Retenção na carreira docente: um estudo exploratório na rede municipal de educação de Diadema. 2011. Trabalho de Conclusão de Curso de Pós-Graduação em Gestão Escolar - Faculdade de Educação - Universidade de São Paulo, São Paulo. 2011.

SCHWARTZ, R. B. Attracting and retaining teachers. OECD Observer, London, n 261, may, 2007. 
UNESCO. Perfil dos professores brasileiros: o que pensam, o que desejam, o que almejam. São Paulo: Unesco, 2004.

VAILLANT, D. Atraer y retener buenos profesionales en la profesión docente: políticas em Latinoamérica. Revista de Educación, Madrid, n. 340, p. 117-140, 2006.

Recebido em 19 de dezembro de 2013.

Aprovado em 24 de outubro de 2014. 